Review

\title{
Mitochondria: A Therapeutic Target for Parkinson's Disease?
}

\author{
Yu Luo ${ }^{1, *}$, Alan Hoffer ${ }^{1}$, Barry Hoffer ${ }^{1}$ and Xin Qi ${ }^{2, *}$
}

1 Department of Neurological Surgery, Case Western Reserve University, Cleveland, OH 44106, USA;

E-Mails: Alan.Hoffer@uhhospitals.org (A.H.); bhoffer@intra.nida.nih.gov (B.H.)

2 Department of Physiology, Case Western Reserve University, Cleveland, OH 44106, USA

* Authors to whom correspondence should be addressed;

E-Mails: yx1710@case.edu (Y.L.); xxq38@case.edu (X.Q.);

Tel.: +1-216-368-4169 (Y.L.); +1-216-368-4459 (X.Q.).

Academic Editors: Jaime M. Ross and Giuseppe Coppotelli

Received: 10 June 2015 / Accepted: 20 August 2015 / Published: 1 September 2015

\begin{abstract}
Parkinson's disease (PD) is one of the most common neurodegenerative disorders. The exact causes of neuronal damage are unknown, but mounting evidence indicates that mitochondrial-mediated pathways contribute to the underlying mechanisms of dopaminergic neuronal cell death both in PD patients and in PD animal models. Mitochondria are organized in a highly dynamic tubular network that is continuously reshaped by opposing processes of fusion and fission. Defects in either fusion or fission, leading to mitochondrial fragmentation, limit mitochondrial motility, decrease energy production and increase oxidative stress, thereby promoting cell dysfunction and death. Thus, the regulation of mitochondrial dynamics processes, such as fusion, fission and mitophagy, represents important mechanisms controlling neuronal cell fate. In this review, we summarize some of the recent evidence supporting that impairment of mitochondrial dynamics, mitophagy and mitochondrial import occurs in cellular and animal PD models and disruption of these processes is a contributing mechanism to cell death in dopaminergic neurons. We also summarize mitochondria-targeting therapeutics in models of PD, proposing that modulation of mitochondrial impairment might be beneficial for drug development toward treatment of PD.
\end{abstract}

Keywords: Parkinson's disease; mitochondrial dysfunction; mitochondrial dynamics 


\section{Introduction}

Parkinson's disease (PD) is the second most common neurodegenerative disorder after Alzheimer's disease, affecting over $1 \%$ of the population older than 60 years of age. Clinically, it is diagnosed primarily based on motor abnormalities including bradykinesia, resting tremor, and cogwheel rigidity [1]. A key characteristic of pathology in PD is the degeneration of the nigrostriatal (NS) dopaminergic pathway which is one of the most important dopamine (DA) pathways in the brain and contains about $80 \%$ of the total brain DA. Despite a large number of studies on the pathogenesis of PD, there is still inconclusive evidence about why dopaminergic neurons are selectively degenerated. Currently, there is no effective restorative treatment available for PD, only symptomatic treatment is available.

Among a number of proposed mechanisms involved in PD pathogenesis, mitochondrial dysfunction has been repeatedly implicated as the cause of the death of DA neurons in PD [2-5]. Mitochondria are critical for many cellular functions, such as intermediary metabolism [6,7], redox signaling [8], calcium homeostasis [9-11], cell proliferation [12,13], development [14,15] and cell death [16-18]. Mitochondrial dysfunction is mainly characterized by the generation of reactive oxygen species (ROS), a defect in mitochondrial electron transport complex enzyme activities, ATP depletion, caspase 3 release and depletion of mitochondrial DNA. In this review, we summarize evidence on the critical involvement of mitochondria in both genetic mutation and environmental toxin-induced PD. We propose a causal role for mitochondrial dysfunction in the development of $\mathrm{PD}$, because (1) neurotoxins causing parkinsonism, such as 1-methyl-4-phenyl-1,2,3,6-tetrahydropyridine (MPTP), rotenone, paraquat, induce dopaminergic neuronal death through direct inhibition of mitochondrial complex I activity; (2) mutant proteins from PD-related genes associate with mitochondria where they elicit diverse mitochondrial dysregulation and subsequently cause neuronal degeneration; (3) therapeutic agents that target mitochondrial protein or inhibit mitochondrial damage can reduce neuropathological phenotypes of PD in animal models and cells from PD patients.

\section{Mitochondrial Dysfunction in Parkinson's Disease}

Aberrant mitochondrial function is one of the major cytopathologies in PD and has been widely accepted as a central pathogenic mechanism underlying PD pathogenesis. Chronic systemic administration of rotenone, a specific complex I inhibitor and a pesticide, results in neuropathologic and behavioral changes in rats that are similar to human PD [19,20]. 1-methyl-4-phenyl-1,2,3,6-tetrahydropyridine (MPTP), a meperidine analog found to cause parkinsonism in humans, exerts its toxic effects through metabolism to 1-methyl-4-phenylpyridinium $\left(\mathrm{MPP}^{+}\right)$, another complex I inhibitor [19,21]. These compounds have long been used in animal models of PD. Furthermore a number of familial forms of PD are associated with mutations in genes encoding both mitochondrially targeted proteins and proteins involved in mitochondrial function and/or oxidative stress responses, including mutations in PINK-1, DJ-1, parkin, and leucine-rich repeat kinase 2 (LRRK2) [22]. Interestingly, one study reported that the size of mitochondria in dopaminergic neurons in the substantia nigra ( $\mathrm{SN}$; susceptible to PD degeneration) is smaller than in neighboring non-dopaminergic neurons or in dopaminergic neurons of the ventral tegmental area which is more resistant in PD, suggesting a basis for the increased vulnerability of SN neurons to subtle changes in mitochondrial maintenance and function [23]. 
In addition, increased oxidative stress due to mitochondrial compromise in PD model animals has been proposed to contribute to the degeneration of dopaminergic neurons [23].

Consistent with the evidence from basic science, clinical studies also showed that mitochondrial damage plays a predominant role in the development of PD in patients. Mild deficiency in mitochondrial respiratory electron transport chain NADH dehydrogenase (Complex I) activity has been reported in the substantia nigra [24] as well as platelets [25,26] and lymphocytes [27,28] in PD patients, suggesting a systemic inhibition of complex I activity in PD patients. Mitochondrial dysfunction could lead to increased oxidative stress. Indeed oxidative damage to lipids, proteins and DNA has been detected in brain tissue from PD patients [29,30]. A recent proteomic analysis of mitochondria-enriched fractions from post-mortem PD substantia nigra revealed differential expression of multiple mitochondrial proteins in PD brains as compared with control brains [23]. In further support for a "mitochondrial genetics" hypothesis for PD pathophysiology, Bender et al. [31] reported higher levels of mitochondrial DNA deletions in nigral neurons from PD patients. Moreover, both Bender et al. [31] and Kraytsberg et al. [32] reported higher levels of mitochondrial DNA deletions in nigral neurons of aged humans with sharp elevations starting shortly before age 70 . This correlates with the known risk factor of age in PD. It is possible that there is an accumulation of mitochondrial dysfunction and of reactive oxygen species (ROS) damage during aging which needs to reach a critical threshold for cellular dysfunction and degeneration to be observed. How a systemic dysregulation in mitochondrial function or oxidative damage leads to tissue or cell type specific vulnerability still remains to be elucidated.

Taken together, although studies over many years on PD indicate an important role of mitochondria in PD-associated pathology, the process by which the mitochondria become dysfunctional in PD and whether correction of mitochondrial defects could provide neuroprotection in PD remain to be determined.

\section{Environmental Toxins that Influence Mitochondrial Function}

Some toxins used to model DA loss in PD, such as MPTP and rotenone, impair respiratory chain function by inhibiting complex I [33-36]. These complex I inhibitors replicate some of the key motor features of PD and lead to DA neuronal loss. Intravenous injection of the compound MPTP by drug addicts caused a condition that closely resembles the anatomic and clinical features of PD [37,38]. Multiple models have been developed in the laboratory in which the chronic infusion of the pesticide rotenone or combination of herbicides and pesticides [39] lead to a pattern of cell death and DA loss similar to that of PD. The precise role of environmental toxins in the cause of PD remains to be defined, but these data support the hypothesis that environmental toxins could introduce mitochondrial dysfunction and lead to parkinsonism in human. Indeed, epidemiological studies showed that the prevalence of sporadic PD is higher among farming communities [40]. Exposure to pesticides or herbicides elicited a three-to fourfold increased risk of developing PD [41]. All of these data suggest an environmental contribution to the etiology of sporadic PD.

\section{Genetic Factors Associated with PD}

In a twin study, Tanner et al. showed that for early onset cases, monozygotic concordance was twice that of dizygotic concordance, suggesting that genetic factors are important in the early onset PD [42]. 
Many examples of familial parkinsonism have also been reported (See review [43]). Mutations of several genes have been linked to familial PD and parkinsonian syndromes [44-46].

\subsection{Mitochondrial DNA Mutations and Deletions in PD}

Mitochondrial DNA (mtDNA) encodes 13 subunits of respiratory chain proteins, including seven complex I, one complex III, three complex IV, and two complex V subunits. Until now, there has been no PD-associated genetic mutations in mtDNA reported [47]. However, mtDNA deletions have been observed in individual dopaminergic neurons dissected from postmortem human substantia nigra tissue [31]. In addition, mutations in the gene encoding human mtDNA polymerase subunit $\gamma$ (POLG) leads to clinical parkinsonism associated with multiple mtDNA deletions. [48,49]. Furthermore, proliferator-activated coactivator-1 $\alpha$ (PGC-1 $\alpha$ ), one of the key regulators of mitochondrial biogenesis, was found to be decreased in PD patients through a genome-wide association study (GWAS) [50]. Directed deletion of transcriptional factor A (TFAM) in mouse DA neurons using the Cre-LoxP system, termed as MitoPark mice, causes marked deletion of mtDNA, severe impairment of oxidative phosphorylation and slowly progressive motor deficits in the DA system that mimic human parkinsonism as well as altered response to L-3,4-dihydroxyphenylalanine (L-DOPA) treatment [51-53]. The MitoPark mice of PD provided direct evidence that mitochondrial dysfunction in DA neurons can causes PD-related phenotypes. Consistently increased level of mtDNA deletions in the striatum of PD patients have been reported [54] and mtDNA deletions were significantly higher in neurons with impaired cytochrome oxidase activity $[31,32]$. These findings support a mitochondrial genetic contribution in PD.

\subsection{Nuclear Gene Mutations Affecting Mitochondrial Function}

Many of the PD susceptible genes identified are related to mitochondrial function (Table 1). These genes and their potential contribution to PD have previously been extensively reviewed [43]. PD linked genes that affect mitochondrial function include, but are not limited to, $\alpha$-synuclein, Parkin, Phosphatase and tensin homologue (PTEN)-induced putative kinase 1 (PINK1), DJ-1 and LRRK2. In this review we will focus on their involvement and effects on dysregulation of mitochondrial dynamics, mitophagy and mitochondrial redox, and mitochondrial protein import.

Alpha-synuclein: $\alpha$-synuclein is aggregation-prone protein which attains an increased propensity to aggregate because of the presence of its hydrophobic non-amyloid $\beta$ component domain. Missense mutations in the alpha-synuclein gene are associated with autosomal dominant PD [55]. The fibrillar form of $\alpha$-synucleinis a major component of Lewy bodies and has been demonstrated to trigger neurotoxicity in $\mathrm{PD}[56,57]$.

Parkin: Parkin is a RING finger containing ubiquitin E3 ligase. It is known to mediate poly-ubiquitination of its substrates for proteasomal degradation. Mutations in the parkin gene cause early onset juvenile autosomal recessive PD, and Parkin mutations are the most common cause of young onset PD. The loss of parkin E3 ligase activity results in accumulation of its substrates leading to neurotoxicity in autosomal recessive $\mathrm{PD}[58,59]$.

PINK1: Phosphatase and tensin homologue (PTEN)-induced putative kinase 1 (PINK1) is a serine/threonine kinase localized in mitochondria. Mutations in PINK1 are associated with a rare form 
of autosomal recessive PD. PINK mutations result in the loss of PINK1 function which leads to aberrant phosphorylation of its substrates to cause PD [60,61].

Table 1. Animal models of Parkinson's disease (PD)-related genes affect mitochondrial function.

\begin{tabular}{|c|c|c|c|c|}
\hline Animal Models & $\begin{array}{c}\text { Genetic Manipulation } \\
\text { in Animals } \\
\end{array}$ & Motor Phenotypes & $\begin{array}{c}\text { PD Pathology and } \\
\text { Mitochondrial Function } \\
\end{array}$ & References \\
\hline \multirow{4}{*}{$\begin{array}{l}\text { Alpha-Synuclein } \\
\text { transgenic mice }\end{array}$} & $\begin{array}{l}\mathrm{hA53T} \text { alpha-Synuclein } \\
\text { in mice; } \mathrm{mPrP} \text { promoter }\end{array}$ & $\begin{array}{l}\text { Severe leading to paralysis } \\
\text { and premature death }\end{array}$ & $\begin{array}{l}\text { Lewy body-like inclusion in } \\
\text { older mice; mitochondrial } \\
\text { dysfunction; no dopaminergic } \\
\text { neuronal loss } \\
\end{array}$ & {$[62-64]$} \\
\hline & $\begin{array}{l}\text { hA30P alpha-synuclein } \\
\text { in mice; } \\
\text { mThy-1 promoter }\end{array}$ & Severe leading to paralysis & $\begin{array}{c}\text { Lewy body-like inclusion; } \\
\text { sensorimotor neuronal loss in } \\
\text { brain stem }\end{array}$ & {$[65]$} \\
\hline & $\begin{array}{c}\text { Alpha-synuclein } \\
\text { overexpression in mice } \\
\text { (Thy1 promoter) }\end{array}$ & $\begin{array}{l}\text { Progressive declines in } \\
\text { spontaneous and } \\
\text { motor activity }\end{array}$ & $\begin{array}{l}\text { No DA neuronal degeneration, } \\
\text { mitochondrial dysregulation }\end{array}$ & {$[66,67]$} \\
\hline & $\begin{array}{l}\text { hA53T alpha-synuclein } \\
\text { expressing in SN DA } \\
\text { neurons of mice }\end{array}$ & $\begin{array}{l}\text { Body weight loss; normal } \\
\text { locomotion activity }\end{array}$ & $\begin{array}{l}\text { Progressive DA neuronal loss; } \\
\text { aberrant mitochondrial inclusion }\end{array}$ & {$[68]$} \\
\hline \multirow{2}{*}{$\begin{array}{l}\text { LRRK2 transgenic } \\
\text { or knock-in mice }\end{array}$} & $\begin{array}{l}\text { LRRK2 R1441G mice; } \\
\text { BAC promoter }\end{array}$ & $\begin{array}{c}\text { Rearing activity decrease in } \\
\text { older mice }\end{array}$ & $\begin{array}{c}\text { DA neurite degeneration; Tau } \\
\text { phosphorylation increase; no DA } \\
\text { neuronal degeneration; } \\
\text { mitochondrial dysfunction }\end{array}$ & {$[69,70]$} \\
\hline & $\begin{array}{l}\text { LRRK2 G2019S } \\
\text { knock-in mice }\end{array}$ & Absent & $\begin{array}{c}\text { Abnormal mitochondrial } \\
\text { morphology; mitochondrial } \\
\text { dysfunction; no DA neuronal loss }\end{array}$ & [71] \\
\hline Parkin $^{-/}$mice & $\begin{array}{l}\text { Parkin germline } \\
\text { inactivation }\end{array}$ & $\begin{array}{c}\text { Conflicting: either absent or } \\
\text { subtle motor movement } \\
\text { disturbance } \\
\end{array}$ & Absent & {$[72,73]$} \\
\hline $\mathrm{DJ} 1^{-/-}$mice & $\begin{array}{l}\text { DJ1 germline } \\
\text { inactivation }\end{array}$ & $\begin{array}{l}\text { Age-dependent declines in } \\
\text { locomotor activity }\end{array}$ & $\begin{array}{c}\text { Impaired DA update; no DA } \\
\text { neuronal degeneration }\end{array}$ & {$[74]$} \\
\hline $\mathrm{PINK}^{-/-}$mice & $\begin{array}{l}\text { PINK1 germline } \\
\text { inactivation }\end{array}$ & $\begin{array}{l}\text { Age-dependent declines in } \\
\text { spontaneous activity }\end{array}$ & $\begin{array}{l}\text { Impaired DA update; no DA } \\
\text { neuronal degeneration; } \\
\text { mitochondrial abnormalities }\end{array}$ & {$[75,76]$} \\
\hline Mito-Park mice & $\begin{array}{l}\text { DAT riven cre; loxed p } \\
\text { TFAM }\end{array}$ & $\begin{array}{c}\text { Begins at } 3-4 \text { months; } \\
\text { declines in spontaneous and } \\
\text { rearing activity }\end{array}$ & $\begin{array}{c}\text { Abnormal mitochondrial } \\
\text { aggregates; DA reduction in the } \\
\text { striatum; progressive DA } \\
\text { neuronal degeneration }\end{array}$ & {$[51]$} \\
\hline $\begin{array}{l}\text { Double-mutant } \\
\text { mice }\end{array}$ & $\begin{array}{l}\text { A53T alpha-synuclein } \\
\text { overexpression in } \\
\text { Parkin }^{-/-} \text {mice }\end{array}$ & Absent & $\begin{array}{c}\text { Altered mitochondrial structure } \\
\text { and morphology; no DA } \\
\text { neuronal loss }\end{array}$ & {$[77]$} \\
\hline
\end{tabular}

$D J-1$ : DJ-1 belongs to the peptidase C56 family of proteins. Wild-type DJ-1 can serve as a chaperone, protease, regulator of transcription and autophagy through redox regulation. DJ-1 seems to be cytoprotective specifically under conditions related to oxidative stress. Its protective action is the result of the modification of cysteine residues on DJ-1 to cysteine-sulfinic and cysteine-sulfonic acids 
under oxidative stress [78]. DJ-1 mutations associated with PD are rare and account for $1 \%-2 \%$ of autosomal recessive early-onset PD [79].

LRRK2: Leucine-rich repeat kinase 2 (LRRK2) is a protein encoded by the PARK8 locus. It has a conserved serine-threonine kinase mitogen-activated protein kinase kinase kinase (MAPKKK) domain, a member of the Roc (Ras of complex) GTPase family [80-82]. To date, there are over 50 variants identified in PD patients. The mutation G2019S (Gly2019 to Ser) that takes place in the MAPKKK domain has been recognized as the most common cause of dominant familial PD and accounts for up to $2 \%$ of sporadic PD cases [83]. The G2019S mutant augments the kinase activity of LRRK2, which is associated with increased toxicity in dopaminergic neurons [84].

\subsection{Mitochondrial Dynamics Impairment in Parkinson's Disease}

Mitochondria are organized in a highly dynamic tubular network that is continuously reshaped by opposing processes of fusion and fission [85]. Mitochondrial fission and fusion were first observed in yeast, and since have been observed in all mammalian cells [86]. A delicate balance is maintained between fusion and fission to ensure the normal function of mitochondria. Specifically the fusion process is important for mitochondrial interactions and communication, and fission facilitates the segregation of mitochondria into daughter cells and enhances mitochondrial renewal and distribution along cytoskeletal tracks. Fusion and fission events enable the proper exchanging and mixing of mitochondrial membranes and contents. This dynamic process controls not only mitochondrial morphology, but also the subcellular location and function of mitochondria. Defects in either fusion or fission limit mitochondrial motility, decrease energy production and increase oxidative stress, thereby promoting cell dysfunction and death [87,88]. The two opposing processes, fusion and fission, are controlled by evolutionarily conserved large GTPases that belong to the dynamin family of proteins. In mammalian cells, mitochondrial fusion is regulated by mitofusin-1 and -2 (MFN1/2) and optic atrophy 1 (OPA1), whereas mitochondrial fission is controlled by the dynamin-1-related protein, (Drp1) [89,90] and its mitochondrial adaptors such as Fis1, Mff and MiD49/51 [91-93]. Drp1 is primarily found in the cytosol, but it translocates from the cytosol to the mitochondrial surface in response to various cellular stimuli to regulate mitochondrial morphology [1]. At the mitochondrial surface, Drp1 is thought to wrap around the mitochondria to induce fission using its GTPase activity [94].

In terms of PD, no mutations in typical mitochondria fission and fusion genes have yet been identified in PD patients. However, increasing evidence from both toxin models and genetic mutations in PD animal models supports the hypothesis that mitochondrial dynamic regulation and dysfunction are involved in PD. Evidence from toxin-induced PD models support a role for mitochondrial fission/fusion in the pathogenesis of PD. The Parkinsonian neurotoxins, 6-hydroxy dopamine (6-OHDA), rotenone, and $\mathrm{MPP}^{+}$, all induce mitochondrial fragmentation, leading to dopaminergic cell death in neuronal cultures $[91,95,96]$. Inhibition of pro-fission Drp1 or overexpression of pro-fusion protein mitofusin-1 (Mfn1) using genetic techniques prevents both neurotoxin-induced mitochondrial fission and neuronal cell death [97-99]. Loss of Mfn2 or conditional knockout of neuronal Mfn2 in mice has recently been reported to result in age-dependent motor deficits, followed by the loss of dopaminergic terminals in the striatum [100,101], suggesting a role for Mfn2 in parkinsonism. Also, Drp1 is required for synaptic formation [102] and lack of Drp1 leads to an impairment of brain development in mice [103,104]. Recently it has been reported that the Drp1 is critical 
for targeting mitochondria to the terminal synapses of dopaminergic neurons and deletion of Drp1 gene in dopaminergic neurons rapidly eliminates DA terminals in the caudate-putamen and causes cell bodies in the midbrain to degenerate and lose $\alpha$-synuclein [105]. Taken together, all these support that molecular machinery which maintains the balance of fusion and fission dynamics in the cells might contribute to the pathogenesis of PD.

In addition, several genes, whose mutated forms are associated with familial PD, affect mitochondrial dynamics: these include PINK1, Parkin, LRRK2 and DJ-1 [45,94,96,106-110]. Among these genes, the role of PINK1/Parkin pathway in regulation of mitochondrial dynamics seems to be opposite from LRRK2 and DJ-1; mutations in PINK1/Parkin lead to mitochondrial fusion [44,111] whereas mutations in LRRK2 or DJ-1 promote mitochondrial fission [44,112]. Fibroblasts from PD patients carrying PINK1 or Parkin mutations exhibited a more fragmented mitochondrial network, showing mitochondrial dysfunction [113,114]. The mitochondrial network could also be reduced by the depletion of Drp1, or overexpression of OPA1 or Mfn2 [115-118]. Deficiency in DJ-1 in cell lines, cultured neurons and lymphoblasts derived from DJ-1-deficient patients displayed aberrant mitochondrial morphology [119]. Further, in double-mutant mice in which alpha-synuclein mutant is overexpressed and parkin is ablated, severe genotype-, age- and region-dependent mitochondrial morphological alterations were found in neuronal somata. The number of structurally altered mitochondria was significantly increased in the SN of these double-mutants mice [77]. These studies further support the involvement of vulnerable genes in mitochondrial dynamics regulation in PD.

Wild-type LRRK2 interacts and colocalizes with several key regulators of mitochondrial fusion/fission, suggesting that it might have multiple regulatory roles [120]. Furthermore, mutant LRRK2 G2019S, the most common mutation in the population of familial PD patients, has been recently demonstrated to interact with Drp1 and to promote mitochondrial fragmentation, leading to mitochondrial dysfunction and neuronal abnormalities [121,122]. This fragmentation can be reduced by expression of the dominant-negative Drp1K38A or overexpression of the fusion protein Mfn2 [121,122]. iPS cells derived from PD patients carrying the G2019S mutation show excessive mitochondrial fission, aberrant autophagy and neuronal damage in DA neurons differentiated in vitro [123]. More importantly, treatment with P110, a selective peptide inhibitor of Drp1 recently developed in Qi's group [124,125], reduced mitochondrial fragmentation and damage, and corrected excessive autophagy. In this study it was also shown that G2019S mutated LRRK2 protein primarily phosphorylates Drp1 at T595 resulting in aberrant mitochondrial fragmentation [123].

Together, these findings suggest that impairment of mitochondrial dynamics might contribute to the pathogenesis and progression of PD.

\section{Mitophagy/Autophagy Impairment in Parkinson's Disease}

Autophagy is a process of cellular degradation in which cargos are degraded by autophagosomes fused with lysosomes [126]. In addition to non-selective cargos, autophagosomes can degrade protein aggregates or damaged mitochondria. Mitochondria-associated autophagy (mitophagy) is regulated by autophagy receptors that preferentially bind ubiquitylated mitochondria and subsequently recruit the autophagosome protein light chain 3 (LC3) through their LC3-interaction region (LIR) motif [127]. LC3 in mammals, also known as Atg8 in yeast, plays crucial roles in both autophagosome membrane biogenesis and cargo 
recognition [128,129]. In yeast, Atg32 functions as a receptor on mitochondria to initiate mitophagy through its interaction with Atg8 [130,131]. In mammals, FUNDC1 [132], p62 [133], BNIP3 [134], and AMBRA1 [135], have been recognized as receptors for mitophagy, all of which bind to LC3 via the LIR motif [136]. The implication of these receptors in mitophagy regulation, however, seems to be dependent of experimental conditions. Whether and how these receptors cooperatively regulate mitophagy remains to be determined.

A number of lines of evidence suggest a critical role for defective autophagy/mitophagy in neurodegeneration in $\mathrm{PD}$. Cultured cells exposed to parkinsonian neurotoxins such as $\mathrm{MPP}^{+}$, rotenone, or 6-OHDA showed an increased number of autophagosomes and associated neuronal cell death $[125,137,138]$. In recent years, PINK1-depenent activation of parkin has been recognized as a major pathway of mitophagy [139]. In mammalian cells, parkin is recruited to depolarized mitochondria, which are subsequently eliminated by autophagy. Such parkin recruitment to mitochondria depends on PINK1 accumulation on mitochondria and therefore PINK1 is a key molecule in the signal transduction of mitophagy [140]. The failure of PINK1/parkin-mediated mitophagic process leads to accumulation of damaged mitochondria, which results in an increase in ROS and cell death [141,142]. Because these studies were all conducted in cells with overexpression of PINK1 and Parkin and because Parkin at endogenous levels fail to mediate mitophagy in PD patient cells [143], the matter of whether these proteins, at the endogenous levels, cooperatively regulate mitophagy remains to be validated. Knock-down of DJ-1, another PD-related gene, resulted in decreased mitochondrial membrane potential, increased reactive oxygen species, excessive mitochondrial fragmentation and impaired autophagy [74,119,144]. Interestingly, overexpression of PINK1 and parkin can rescue mitochondrial fragmentation and dysfunction induced by the depletion of DJ-1 [145,146]. Given that wild-type and mutant DJ-1 can interact with PINK1 [147] and that Parkin, as an E3 ligase on mitochondria, catalyzes the ubiquitination of DJ-1 [148], PINK1, Parkin and DJ-1 may be operative in the pathway of PINK1/parkin-mediated mitophagy.

Pathogenic LRRK2-mediated autophagy has been observed in a variety of cell cultures $[149,150]$, in neurons derived from patient-induced pluripotent stem cells [151] and in animal models in which a mutant form of LRRK2 is expressed [152]. Either knock-down of LRRK2 by siRNA or treatment with a LRRK2 kinase inhibitor caused an increase in autophagic fluxin-cultured cells [153,154]. Overexpression of LRRK2, especially mutant forms, seems to suppress autophagy [155]. In contrast, studies from other two groups show that mutant forms of LRRK2 may induce autophagy via an ERK1/2-dependent pathway $[149,156]$. Although the detailed mechanisms by which LRRK2 and its mutants mediate autophagy are not clear, LRRK2 may disrupt the balance of autophagy through damaging lysosome-related calcium storage and cargo degradation [157,158]. Further, our group recently reported excessive mitophagy in a variety of cells expressing the LRRK2 G2019S mutant, which was accompanied by mitochondrial depolarization, recruitment of p62 to the mitochondria, increased LC3II levels and lysosomal activity as well as death of dopaminergic neurons [123,159]. We showed that the LRRK2 G2019S mutant caused excessive mitophagyby phosphorylating its substrate including fission protein Drp1 and mitochondrial outer membrane protein $\mathrm{Bcl}_{2}$ [123,159]. Thus, the pathway that LRRK2 mediation of mitophagy might be different from those occurred during autophagy.

Taken together, a large body of studies indicates that the different PD-related genes contribute to the pathogenesis of $\mathrm{PD}$ at the intersection of mitochondrial dysfunction and autophagy. The loss of mitochondrial membrane potential, which is associated with mitochondrial dysfunction, seems to be a 
common signal for mitochondria to be degraded via mitophagy. Moreover, occurrence of mitochondrial fragmentation due to impairment of mitochondrial fusion and fission often precedes the induction of mitophagy. Thus, it is possible that mitophagy may be a multistep process starting with the degradation of profusion/fission proteins, resulting in an imbalance of mitochondrial dynamics and the subsequent clearance of mitochondria [86]. However, the factors that regulate these processes involved in mitochondrial "quality control", including mitochondrial dynamics, mitochondria-associated degradation and mitophagy in PD, remain to be determined.

\section{Mitochondrial Redox Signaling in Parkinson's Disease}

Decreased Complex I activity in the SN of PD patients and animal models has been repeatedly observed. The defect in complex I results in impairment of electron transport and causes ROS accumulation in mitochondria which lead to neuronal degeneration. Neurotoxins causing parkinsonism, $\mathrm{MPP}^{+}$are selectively taken up into dopaminergic neurons in which it inhibits Complex I activity [160]. Rotenone also inhibits Complex I by impairing oxidative phosphorylation [161]. These studies demonstrate a contribution from ROS to the pathogenesis of dopamine neuronal loss in PD. The genetic PD-linked proteins play a significant role in this process. Alpha-synuclein mutant A53T can enter mitochondria where it binds to the Complex I subunit to inhibit Complex I activity, producing ROS [162,163]. Functional studies showed that alpha-synuclein associated with mitochondria induces cytochrome c release, increased calcium and ROS levels resulting in dopaminergic neuronal death [164]. In addition, expression of mutants of PD-related genes Parkin, PINK1, DJ-1 and LRRK2 in cultured cells all increased ROS. This evidence has been well-summarized in other reviews $[29,165]$. However, it is uncertain if such elevated ROS are directly caused by these mutants or through indirect cellular effects.

Besides ROS, reactive nitrogen species (RNS) mediating nitrosative stress is also implicated in SN neuronal loss in PD [166]. RNS are generated by the reaction of superoxide with nitric oxide (NO), which results in the production of peroxynitrite. NO inhibits several enzymes including complexes I and IV of the mitochondrial electron transport chain, which in turn lead to ROS generation [167,168]. Increased expression of iNOS and nNOS were observed in basal ganglia of postmortem brain of PD patients [169]. In the mouse MPTP model, there was a significant upregulation of iNOS associated with the gliosis in the SN [170]. Inhibition of nNOS has been reported to protect against neurotoxicity in MPTP-induced PD animal model [171,172]. These observations suggest that NO and its metabolite peroxynitriteare implicated in the pathogenesis of PD.

\section{Mitochondrial Protein Import in Parkinson's Disease}

Mitochondria possess their own DNA and translational machinery; however, there are only a small number of mitochondrial proteins encoded by mtDNA that are synthesized within the organelle. The majority of mitochondrial proteins are nuclear-encoded and have to be imported into the organelle. The translocase of the outer mitochondrial membrane (TOM complex) plays central roles in controlling protein entry to mitochondria [173]. The TOM complex is the main entry portal for most mitochondrial proteins that are synthesized in cytoplasm. The TOM complex contains seven subunits including TOM40, TOM22, two proprotein receptors, TOM20, and TOM70, and three smaller proteins, TOM5, TOM6 and TOM7. In general, imported proteins bind to one of these receptors. With the assistance of TOM22 and TOM5, the 
imported proteins pass the TOM 40 channel [174]. TOM complexes also need to cooperate with TIM (Translocase of the Inner Membrane) 23 complexes to import matrix-targeted proteins [175]. Thus, the TOM and the TIM23 complex direct the translocation of oxidative phosphorylation and metabolite transporter proteins to the inner membrane.

A number of studies have reported that PD-associated genes, alpha-synuclein, PINK1 and Parkin can interact with the TOM complex, disrupting the mitochondrial protein import. Alpha-synuclein can enter mitochondria where it mainly localizes at the inner membrane. The import of alpha-synuclein to mitochondria is through the TOM complex [176,177]. In postmortem brain samples of PD and in brain tissues of mice overexpressing alpha-synuclein, TOM 40 levels changed together with the levels of alpha-synuclein [177]. Expression with either wild-type alpha-synuclein or mutant A53T in cultured cells resulted in the loss of TOM40, whereas over-expression of TOM40 prevented the cellular damage caused by expression of either alpha-synuclein wild-type or its mutant A53T [177]. Thus, alpha-synuclein mutants may impair mitochondrial function by suppression of TOM40-dependent mitochondrial protein import pathways. PINK1 is also imported into the mitochondria via the TOM complex channel $[178,179]$ and then is degraded in a membrane potential-dependent manner. Under mitochondrial depolarization PINK1, interacting with the TOM complex, recruits and activates Parkin, leading to degradation of mitochondrial outer membrane proteins and ultimately mitophagy [178]. Thus, pathogenic mutations in PINK1 and parkin may disrupt this pathway, resulting in the accumulation of dysfunctional mitochondria.

\section{Potential Therapeutics Targeting Mitochondria for Treatment of PD}

Given the importance of mitochondrial dysfunction in the pathogenesis of PD, therapeutics targeting mitochondria have been studied to prevent or treat PD. Although the cellular and pathological phenotypes from neurotoxin-induced and genetic mutant-associated PD models are different, the outcomes of mitochondrial dysfunction, including mitochondrial dynamic impairments, increased ROS, and impaired bioenergetics, seem to be common pathways. Thus, the mechanistic information on mitochondrial dysfunction in PD models provides potential targets for the development of therapeutic approaches for treatment of PD.

Here, we summarize reported therapeutic agents that reduce PD pathology in models of PD (see Table 2). We categorize these agents into (1) modulating PD-related genetic mutants; (2) modulating mitochondrial proteins; and (3) modulating the consequences of mitochondrial dysfunction. In Table 2, we list the neuroprotective effects of these agents especially in either animal models of PD or neuron derived patient-iPS cells.

Modulating PD-related genetic mutants: LRRK2 mutants are the most common genetic mutants in both familial and sporadic PD. Modulation of the LRRK2 kinase domain has been attractive for the development of therapeutics of PD. LRRK2 inhibitors, PF-06447475 and GW5074, have been shown to increase dopaminergic neuronal survival in primary neuronal cultures and neurons- derived from patient iPS cells $[180,181]$. Increasing glyoxalase activity of DJ-1 by supplying D-lactate and glycolate rescues the requirement for DJ-1 in maintenance of mitochondrial potential, increases cytocatalytic rate of DJ-1, and reduces neuronal death caused by paraquat and down-regulation of PINK1 [182]. However, thus far, these reagents are only tested in cultured cells so far. Whether treatment with these pharmacological agents protect neurons from PD in animal models remains to be determined. 
Table 2. Therapeutic agents that target mitochondria for treatment of Parkinson's disease

\begin{tabular}{|c|c|c|c|c|}
\hline Category & Agent & Molecular Action & PD Mode & Therapeutic Effects \\
\hline \multirow{3}{*}{ Modulating PD-related genes } & PF-06447475 & LRRK2 kinase inhibitor & Transgenic rat with LRRK2 G2019S & $\begin{array}{l}\text { Reduce behavioral and neuropathological phenotypes } \\
\text { Reduce inflammation [183] }\end{array}$ \\
\hline & GW5074 & LRRK2 kinase inhibitor & DA neurons derived from PD patient iPS cells & $\begin{array}{c}\text { Suppression of ROS } \\
\text { Improve mitochondrial respiration } \\
\text { Increase DA neuronal survival [180] }\end{array}$ \\
\hline & FX2149 & LRRK2 GTPase inhibitor & mouse inflammation model & $\begin{array}{c}\text { Reduce neuroinflammation } \\
\text { Inhibit microglial activity [184] }\end{array}$ \\
\hline \multirow{4}{*}{ Modulating mitochondrial protein } & Alda-1 & ALDH2 activator & Rotenone- and MPTP-induced animal models & $\begin{array}{l}\text { Improve mitochondrial membrane potential } \\
\text { Inhibit mitochondrial ROS } \\
\text { Reduce dopaminergic cell death [185] }\end{array}$ \\
\hline & TRO40303 & $\begin{array}{l}\text { inhibitor of mitochondrial } \\
\text { transition pore }\end{array}$ & Mice expressing alha-synuclein & $\begin{array}{l}\text { Upregulate mitochondrial proteins } \\
\text { Increase TH expression [186] }\end{array}$ \\
\hline & P110 & Peptide inhibitor of Drp1 & $\begin{array}{l}\text { DA neurons from LRRK2 G2019S PD patient } \\
\text { iPS cells }\end{array}$ & $\begin{array}{l}\text { Improve mitochondrial membrane potential } \\
\text { Inhibit mitochondrial ROS } \\
\text { Increase mitochondrial integrity } \\
\text { Reduce autophagy } \\
\text { Improve DA neuronal morphology and survival [123] }\end{array}$ \\
\hline & Mdivi-1 & $\begin{array}{l}\text { Inhibitor of mitochondrial } \\
\text { fragmentation }\end{array}$ & $\begin{array}{l}\text { MPTP-induced mouse PD model } \\
\text { PINK1 } 1^{-/} \text {mouse model }\end{array}$ & $\begin{array}{l}\text { Improve mitochondrial morphology } \\
\text { Improve mouse behavioral outcome } \\
\text { Reduce DA neuronal loss in SN } \\
\text { Restore dopamine level [187] }\end{array}$ \\
\hline
\end{tabular}


Table 2. Cont.

\begin{tabular}{|c|c|c|c|c|}
\hline Category & Agent & Molecular Action & PD Mode & Therapeutic Effects \\
\hline \multirow{8}{*}{ Modulating mitochondrial dysfunction } & Q1 & 8-OH-quinoline-based iron chelator & MPTP-induced mouse PD model & $\begin{array}{c}\text { Reduce DA neuronal degeneration in SN } \\
\text { Decrease mitochondrial iron pool [188] }\end{array}$ \\
\hline & Rapamycin & mTOR inhibitor & 6-OHDA-induced rat PD model & $\begin{array}{c}\text { Inhibit oxidative stress } \\
\text { Inhibit mitochondrial apoptosis [189] }\end{array}$ \\
\hline & Edaravone & ROS scavenger & Rotenone-induced rat PD model & $\begin{array}{l}\text { Inhibit mitochondrial apoptosis } \\
\text { Reduce ROS [190] }\end{array}$ \\
\hline & Melatonin & Antioxidant & $\begin{array}{l}\text { Rotenone-induced rat PD model } \\
\text { 6-OHDA-induced rat PD model }\end{array}$ & $\begin{array}{c}\text { Suppress calcium level } \\
\text { Inhibit mitochondrial ROS } \\
\text { Enhance complex I activity }[191,192]\end{array}$ \\
\hline & Quercetin & Bioflavonoid & Rotenone-induced rat PD model & $\begin{array}{c}\text { Inhibit mitochondrial ROS generation } \\
\text { Inhibit p53 level } \\
\text { Inhibit nuclear translocation of NF-kappaB } \\
\text { Inhibit mitochondrial apoptosis [193] }\end{array}$ \\
\hline & CNB-001 & Curcumin derivative & MPTP-induced mouse PD model & $\begin{array}{l}\text { Improve mitochondrial morphology } \\
\text { Inhibit mitochondrial apoptotic pathway } \\
\text { Improve mitochondrial membrane potential [194] }\end{array}$ \\
\hline & Alpha-Lipoic acid & Antioxidant & Rotenone-induced rat PD model & $\begin{array}{c}\text { Increase mitochondrial complex I activity } \\
\text { Inhibit ROS generation } \\
\text { Increase mitochondrial biogenesis } \\
\text { Increase glutathione [195] }\end{array}$ \\
\hline & Lycopene & Chemical carotene & Rotenone-induced rat PD model & $\begin{array}{l}\text { Inhibit mitochondrial apoptotic pathway } \\
\text { Increase SOD activity } \\
\text { Increase glutathione } \\
\text { Inhibit lipid peroxidation [196] } \\
\end{array}$ \\
\hline
\end{tabular}


Modulating mitochondrial proteins: Aldehyde dehydrogenase 2 (ALDH2), located in mitochondrial matrix, functions as a cellular protector against oxidative stress by detoxification of cytotoxic aldehydes. Alda-1 is a small molecule that enhances ALDH enzyme activity and protects against oxidative toxicity [197]. Treatment with Alda-1 can reduce rotenone-induced apoptosis in both SH-SY5Y cells and primary dopaminergic neurons. Moreover, intraperitoneal administration of Alda-1 can improve mitochondrial membrane potential, inhibit mitochondrial ROS and reduce death of tyrosine hydroxylase (TH)-positive dopaminergic neurons in rotenone- or MPTP-induced PD animal models [185]. Cholesterol oximes such as olesoxime and TRO40303 are small molecules that interact with the mitochondrial outer membrane protein VDAC and limit opening of the mitochondrial transition pore in response to oxidative stress [198]. Olesoxime can protect differentiated SHSY-5Y cells from cell death, and reduce neurite retraction and cytoplasmic shrinkage induced by alpha-synuclein overexpression [199]. Low dose TRO40303 upregulates a number of mitochondrial proteins including Drp1 and VDAC and enhances expression of tyrosine hydroxylase in mice overexpressing alpha-synuclein [186]. As mentioned above, our group has developed a peptide inhibitor P110 that selectively blocks the protein-protein interactions between Drp1 and its mitochondrial adaptor Fis1 [125]. Treatment with P110 significantly reduced mitochondrial fragmentation, decreased mitochondrial ROS and improved mitochondrial integrity in dopaminergic neurons exposed to $\mathrm{MPP}^{+}$in neurons expressing the LRRK2 G2019S mutation, and in dopaminergic neurons derived from LRRK2 G2019S patient-iPS cells [123,125]. Importantly, we showed that treatment with P110 had minor effects on mitochondrial dynamics and neuronal survival under physiological conditions [123,125]. In addition, Mdivi-1, an inhibitor of mitochondrial fragmentation, was reported to reduce behavioral and neuropathological phenotypes in an MPTP-induced PD mouse model, in addition to its protective effects in dopaminergic neurons exposed to neurotoxins [187].

Modulating the consequences of mitochondrial dysfunction: Modulation of downstream mitochondrial dysfunction may also provide therapeutic opportunities, in both sporadic and familial PD. In the past decades, a number of natural products and small molecules have been reported to protect against neuropathology associated with $\mathrm{PD}$, at least in part through protecting mitochondria. Treatment with these agents has been shown to reduce mitochondrial ROS, inhibit mitochondrial apoptotic pathways, and increase mitochondrial complex I activity. As a consequence, treatment with these agents can reduce neuronal degeneration in PD in culture and in animals. These agents have been extensively reviewed [200-203]. Here, we only list those that have significant protection in animal models of PD (Table 2).

\section{Concluding Remarks}

Accumulating evidence supports the hypothesis that mitochondrial abnormalities and dysfunction could critically influence neuronal degeneration in both sporadic and faimilial PD. Dysregulation of mitochondrial dynamics and mitophagy have been centrally implicated in the neuropathology of PD. This evidence supports the idea that mitochondrial damage might be a primary cause initiating the progression of PD. Thus, targeting mitochondria may offer the opportunities for drug development to treat neurodegenerative diseases such as parkinsonism. 


\section{Conflicts of Interest}

The authors declare no conflict of interest.

\section{References}

1. Duvoisin, R.C. Overview of Parkinson's disease. Ann. N. Y. Acad. Sci. 1992, 648, 187-193.

2. Dauer, W.; Przedborski, S. Parkinson's disease: Mechanisms and models. Neuron 2003, 39, 889-909.

3. Dawson, T.M.; Dawson, V.L. Molecular pathways of neurodegeneration in Parkinson's disease. Science 2003, 302, 819-822.

4. Yao, Z.; Wood, N.W. Cell death pathways in Parkinson's disease: Role of mitochondria. Antioxid. Redox Signal. 2009, 11, 2135-2149.

5. Ellis, C.E.; Murphy, E.J.; Mitchell, D.C.; Golovko, M.Y.; Scaglia, F.; Barcelo-Coblijn, G.C.; Nussbaum, R.L. Mitochondrial lipid abnormality and electron transport chain impairment in mice lacking alpha-synuclein. Mol. Cell. Biol. 2005, 25, 10190-10201.

6. Herrmann, J.M.; Longen, S.; Weckbecker, D.; Depuydt, M. Biogenesis of mitochondrial proteins. Adv. Exp. Med. Biol. 2012, 748, 41-64.

7. Sas, K.; Robotka, H.; Toldi, J.; Vecsei, L. Mitochondria, metabolic disturbances, oxidative stress and the kynurenine system, with focus on neurodegenerative disorders. J. Neurol. Sci. 2007, 257, 221-239.

8. Daiber, A. Redox signaling (cross-talk) from and to mitochondria involves mitochondrial pores and reactive oxygen species. Biochim. Biophys. Acta 2010, 1797, 897-906.

9. Bononi, A.; Missiroli, S.; Poletti, F.; Suski, J.M.; Agnoletto, C.; Bonora, M.; de Marchi, E.; Giorgi, C.; Marchi, S.; Patergnani, S.; et al. Mitochondria-associated membranes (MAMs) as hotspot $\mathrm{Ca}^{2+}$ signaling units. Adv. Exp. Med. Biol. 2012, 740, 411-437.

10. Rizzuto, R.; de Stefani, D.; Raffaello, A.; Mammucari, C. Mitochondria as sensors and regulators of calcium signalling. Nat. Rev. Mol. Cell Biol. 2012, 13, 566-578.

11. Cali, T.; Ottolini, D.; Brini, M. Mitochondrial $\mathrm{Ca}^{2+}$ as a key regulator of mitochondrial activities. Adv. Exp. Med. Biol. 2012, 942, 53-73.

12. Osteryoung, K.W.; Nunnari, J. The division of endosymbiotic organelles. Science 2003, 302, 1698-704.

13. Antico Arciuch, V.G.; Elguero, M.E.; Poderoso, J.J.; Carreras, M.C. Mitochondrial regulation of cell cycle and proliferation. Antioxid. Redox Signal. 2012, 16, 1150-1180.

14. Moyes, C.D.; Hood, D.A. Origins and consequences of mitochondrial variation in vertebrate muscle. Annu. Rev. Physiol. 2003, 65, 177-201.

15. Schatten, H.; Prather, R.S.; Sun, Q.Y. The significance of mitochondria for embryo development in cloned farm animals. Mitochondrion 2005, 5, 303-321.

16. Giorgi, C.; Baldassari, F.; Bononi, A.; Bonora, M.; de Marchi, E.; Marchi, S.; Missiroli, S.; Patergnani, S.; Rimessi, A.; Suski, J.M.; et al. Mitochondrial $\mathrm{Ca}^{2+}$ and apoptosis. Cell Calcium 2012, 52, 36-43. 
17. Rasola, A.; Bernardi, P. Mitochondrial permeability transition in $\mathrm{Ca}^{2+}$-dependent apoptosis and necrosis. Cell Calcium 2011, 50, 222-233.

18. Wang, C.; Youle, R.J. The role of mitochondria in apoptosis*. Annu. Rev. Genet. 2009, 43, 95-118.

19. Burbach, J.P.; Smits, S.; Smidt, M.P. Transcription factors in the development of midbrain dopamine neurons. Ann. N. Y. Acad. Sci. 2003, 991, 61-68.

20. Wallen, A.; Perlmann, T. Transcriptional control of dopamine neuron development. Ann. N. Y. Acad. Sci. 2003, 991, 48-60.

21. Dreyer, S.D.; Zhou, G.; Baldini, A.; Winterpacht, A.; Zabel, B.; Cole, W.; Johnson, R.L.; Lee, B. Mutations in LMX1B cause abnormal skeletal patterning and renal dysplasia in nail patella syndrome. Nat. Genet. 1998, 19, 47-50.

22. Smidt, M.P.; van Schaick, H.S.; Lanctot, C.; Tremblay, J.J.; Cox, J.J.; van der Kleij, A.A.; Wolterink, G.; Drouin, J.; Burbach, J.P. A homeodomain gene Ptx3 has highly restricted brain expression in mesencephalic dopaminergic neurons. Proc. Natl Acad. Sci. USA 1997, 94, 13305-13310.

23. Smidt, M.P.; Asbreuk, C.H.; Cox, J.J.; Chen, H.; Johnson, R.L.; Burbach, J.P. A second independent pathway for development of mesencephalic dopaminergic neurons requires Lmx1b. Nat. Neurosci. 2000, 3, 337-341.

24. Mann, V.M.; Cooper, J.M.; Daniel, S.E.; Srai, K.; Jenner, P.; Marsden, C.D.; Schapira, A.H. Complex I, iron, and ferritin in Parkinson's disease substantia nigra. Ann. Neurol. 1994, 36, 876-881.

25. Blandini, F.; Nappi, G.; Greenamyre, J.T. Quantitative study of mitochondrial complex I in platelets of parkinsonian patients. Mov. Disord. 1998, 13, 11-15.

26. Haas, R.H.; Nasirian, F.; Nakano, K.; Ward, D.; Pay, M.; Hill, R.; Shults, C.W. Low platelet mitochondrial complex I and complex II/III activity in early untreated Parkinson's disease. Ann. Neurol. 1995, 37, 714-722.

27. Barroso, N.; Campos, Y.; Huertas, R.; Esteban, J.; Molina, J.A.; Alonso, A.; Gutierrez-Rivas, E.; Arenas, J. Respiratory chain enzyme activities in lymphocytes from untreated patients with Parkinson disease. Clin. Chem. 1993, 39, 667-69.

28. Yoshino, H.; Nakagawa-Hattori, Y.; Kondo, T.; Mizuno, Y. Mitochondrial complex I and II activities of lymphocytes and platelets in Parkinson's disease. J. Neural Transm Parkinsons Dis. Dement. Sect. 1992, 4, 27-34.

29. Dias, V.; Junn, E.; Mouradian, M.M. The role of oxidative stress in Parkinson's disease. J. Parkinsons Dis. 2013, 3, 461-491.

30. Hwang, O. Role of oxidative stress in Parkinson's disease. Exp. Neurobiol. 2013, 22, 11-17.

31. Bender, A.; Krishnan, K.J.; Morris, C.M.; Taylor, G.A.; Reeve, A.K.; Perry, R.H.; Jaros, E.; Hersheson, J.S.; Betts, J.; Klopstock, T.; et al. High levels of mitochondrial DNA deletions in substantia nigra neurons in aging and Parkinson disease. Nat. Genet. 2006, 38, 515-517.

32. Kraytsberg, Y.; Kudryavtseva, E.; McKee, A.C.; Geula, C.; Kowall, N.W.; Khrapko, K. Mitochondrial DNA deletions are abundant and cause functional impairment in aged human substantia nigra neurons. Nat. Genet. 2006, 38, 518-520.

33. Langston, J.W.; Ballard, P.; Tetrud, J.W.; Irwin, I. Chronic Parkinsonism in humans due to a product of meperidine-analog synthesis. Science 1983, 219, 979-980. 
34. Betarbet, R.; Sherer, T.B.; MacKenzie, G.; Garcia-Osuna, M.; Panov, A.V.; Greenamyre, J.T. Chronic systemic pesticide exposure reproduces features of Parkinson's disease. Nat. Neurosci. 2000, 3, 1301-1306.

35. Testa, C.M.; Sherer, T.B.; Greenamyre, J.T. Rotenone induces oxidative stress and dopaminergic neuron damage in organotypic substantia nigra cultures. Brain Res. Mol. Brain Res. 2005, 134, 109-118.

36. Smeyne, R.J.; Jackson-Lewis, V. The MPTP model of Parkinson's disease. Brain Res. Mol. Brain Res. 2005, 134, 57-66.

37. Langston, J.W.; Ballard, P.A., Jr. Parkinson's disease in a chemist working with 1-methyl-4phenyl-1,2,5,6-tetrahydropyridine. N. Engl. J. Med. 1983, 309, 310.

38. Kopin, I.J. Toxins and Parkinson's disease: MPTP parkinsonism in humans and animals. Adv. Neurol. 1987, 45, 137-144.

39. Barbeau, A. Parkinson's disease: Clinical features and etiopahthology. In Amsterdam Handbook of Clinical Neurology; Viken, P.J., Bruyn, G.W., Klawans, H.L., Eds.; Elsevier Science Publishers: Amsterdam, The Netherlands, 1986; pp. 87-108.

40. Jenner, P.; Olanow, C.W. Understanding cell death in Parkinson's disease. Ann. Neurol. 1998, 44 (Suppl. 1), S72-S84.

41. Nunes, I.; Tovmasian, L.T.; Silva, R.M.; Burke, R.E.; Goff, S.P. Pitx3 is required for development of substantia nigra dopaminergic neurons. Proc. Natl. Acad. Sci. USA 2003, 100, 4245-4250.

42. Van den Munckhof, P.; Luk, K.C.; Ste-Marie, L.; Montgomery, J.; Blanchet, P.J.; Sadikot, A.F.; Drouin, J. Pitx3 is required for motor activity and for survival of a subset of midbrain dopaminergic neurons. Development 2003, 130, 2535-2542.

43. Klein, C.; Westenberger, A. Genetics of Parkinson's disease. Cold Spring Harb. Perspect. Med. 2012, 2, a008888.

44. Zetterstrom, R.H.; Solomin, L.; Jansson, L.; Hoffer, B.J.; Olson, L.; Perlmann, T. Dopamine neuron agenesis in Nurr1-deficient mice. Science 1997, 276, 248-250.

45. Wallen, A.; Zetterstrom, R.H.; Solomin, L.; Arvidsson, M.; Olson, L.; Perlmann, T. Fate of mesencephalic AHD2-expressing dopamine progenitor cells in NURR1 mutant mice. Exp. Cell Res. 1999, 253, 737-46.

46. Smidt, M.P.; Smits, S.M.; Burbach, J.P. Molecular mechanisms underlying midbrain dopamine neuron development and function. Eur. J. Pharmacol. 2003, 480, 75-88.

47. Franco-Iborra, S.; Vila, M.; Perier, C. The Parkinson Disease Mitochondrial Hypothesis: Where Are We at? Neuroscientist 2015, doi:10.1177/1073858415574600.

48. Luoma, P.; Melberg, A.; Rinne, J.O.; Kaukonen, J.A.; Nupponen, N.N.; Chalmers, R.M.; Oldfors, A.; Rautakorpi, I.; Peltonen, L.; Majamaa, K.; et al. Parkinsonism, premature menopause, and mitochondrial DNA polymerase gamma mutations: Clinical and molecular genetic study. Lancet 2004, 364, 875-882.

49. Henchcliffe, C.; Beal, M.F. Mitochondrial biology and oxidative stress in Parkinson disease pathogenesis. Nat. Clin. Pract. Neurol. 2008, 4, 600-609. 
50. Zheng, B.; Liao, Z.; Locascio, J.J.; Lesniak, K.A.; Roderick, S.S.; Watt, M.L.; Eklund, A.C.; Zhang-James, Y.; Kim, P.D.; Hauser, M.A.; et al. PGC-1 $\alpha$, a potential therapeutic target for early intervention in Parkinson's disease. Sci. Transl Med. 2010, 2, 52 ra73.

51. Ekstrand, M.I.; Terzioglu, M.; Galter, D.; Zhu, S.; Hofstetter, C.; Lindqvist, E.; Thams, S.; Bergstrand, A.; Hansson, F.S.; Trifunovic, A.; et al. Progressive parkinsonism in mice with respiratory-chain-deficient dopamine neurons. Proc. Natl. Acad. Sci. USA 2007, 104, 1325-1330.

52. Ekstrand, M.I.; Galter, D. The MitoPark Mouse-An animal model of Parkinson's disease with impaired respiratory chain function in dopamine neurons. Parkinsonism Relat. Disord. 2009, 15 (Suppl. 3), S185-S188.

53. Gellhaar, S.; Marcellino, D.; Abrams, M.B.; Galter, D. Chronic L-DOPA induces hyperactivity, normalization of gait and dyskinetic behavior in MitoPark mice. Genes Brain Behav. 2015, 14, 260-270.

54. Ikebe, S.; Tanaka, M.; Ohno, K.; Sato, W.; Hattori, K.; Kondo, T.; Mizuno, Y.; Ozawa, T. Increase of deleted mitochondrial DNA in the striatum in Parkinson's disease and senescence. Biochem. Biophys. Res. Commun. 1990, 170, 1044-1048.

55. Lee, V.M.; Trojanowski, J.Q. Mechanisms of Parkinson's disease linked to pathological alpha-synuclein: New targets for drug discovery. Neuron 2006, 52, 33-38.

56. Peelaerts, W.; Bousset, L.; van der Perren, A.; Moskalyuk, A.; Pulizzi, R.; Giugliano, M.; van den Haute, C.; Melki, R.; Baekelandt, V. Synuclein strains cause distinct synucleinopathies after local and systemic administration. Nature 2015, 522, 340-344.

57. Selkoe, D.; Dettmer, U.; Luth, E.; Kim, N.; Newman, A.; Bartels, T. Defining the native state of alpha-synuclein. Neurodegener. Dis. 2014, 13, 114-117.

58. Riess, O.; Jakes, R.; Kruger, R. Genetic dissection of familial Parkinson's disease. Mol. Med. Today 1998, 4, 438-444.

59. De Silva, H.R.; Khan, N.L.; Wood, N.W. The genetics of Parkinson's disease. Curr. Opin. Genet. Dev. 2000, 10, 292-298.

60. Tan, J.M.; Dawson, T.M. Parkin blushed by PINK1. Neuron 2006, 50, 527-529.

61. Kubo, S.; Hattori, N.; Mizuno, Y. Recessive Parkinson's disease. Mov. Disord. 2006, 21, 885-893.

62. Giasson, B.I.; Duda, J.E.; Quinn, S.M.; Zhang, B.; Trojanowski, J.Q.; Lee, V.M. Neuronal alpha-synucleinopathy with severe movement disorder in mice expressing A53T human alpha-synuclein. Neuron 2002, 34, 521-533.

63. Lee, M.K.; Stirling, W.; Xu, Y.; Xu, X.; Qui, D.; Mandir, A.S.; Dawson, T.M.; Copeland, N.G.; Jenkins, N.A.; Price, D.L. Human alpha-synuclein-harboring familial Parkinson's disease-linked Ala-53 $\rightarrow$ Thr mutation causes neurodegenerative disease with alpha-synuclein aggregation in transgenic mice. Proc. Natl. Acad. Sci. USA 2002, 99, 8968-8973.

64. Gispert, S.; Del Turco, D.; Garrett, L.; Chen, A.; Bernard, D.J.; Hamm-Clement, J.; Korf, H.W.; Deller, T.; Braak, H.; Auburger, G.; et al. Transgenic mice expressing mutant A53T human alpha-synuclein show neuronal dysfunction in the absence of aggregate formation. Mol. Cell. Neurosci. 2003, 24, 419-429. 
65. Neumann, M.; Kahle, P.J.; Giasson, B.I.; Ozmen, L.; Borroni, E.; Spooren, W.; Muller, V.; Odoy, S.; Fujiwara, H.; Hasegawa, M.; et al. Misfolded proteinase K-resistant hyperphosphorylated alpha-synuclein in aged transgenic mice with locomotor deterioration and in human alpha-synucleinopathies. J. Clin. Investig. 2002, 110, 1429-11439.

66. Rockenstein, E.; Mallory, M.; Hashimoto, M.; Song, D.; Shults, C.W.; Lang, I.; Masliah, E. Differential neuropathological alterations in transgenic mice expressing alpha-synuclein from the platelet-derived growth factor and Thy-1 promoters. J. Neurosci. Res. 2002, 68, 568-578.

67. Fleming, S.M.; Salcedo, J.; Fernagut, P.O.; Rockenstein, E.; Masliah, E.; Levine, M.S.; Chesselet, M.F. Early and progressive sensorimotor anomalies in mice overexpressing wild-type human alpha-synuclein. J. Neurosci. 2004, 24, 9434-9440.

68. Chen, L.; Xie, Z.; Turkson, S.; Zhuang, X. A53T human alpha-synuclein overexpression in transgenic mice induces pervasive mitochondria macroautophagy defects preceding dopamine neuron degeneration. J. Neurosci. 2015, 35, 890-905.

69. Li, Y.; Liu, W.; Oo, T.F.; Wang, L.; Tang, Y.; Jackson-Lewis, V.; Zhou, C.; Geghman, K.; Bogdanov, M.; Przedborski, S.; et al. Mutant LRRK2(R1441G) BAC transgenic mice recapitulate cardinal features of Parkinson's disease. Nat. Neurosci. 2009, 12, 826-828.

70. Dranka, B.P.; Gifford, A.; McAllister, D.; Zielonka, J.; Joseph, J.; O'Hara, C.L.; Stucky, C.L.; Kanthasamy, A.G.; Kalyanaraman, B. A novel mitochondrially-targeted apocynin derivative prevents hyposmia and loss of motor function in the leucine-rich repeat kinase 2 (LRRK2(R1441G)) transgenic mouse model of Parkinson's disease. Neurosci. Lett. 2014, 583, 159-164.

71. Yue, M.; Hinkle, K.M.; Davies, P.; Trushina, E.; Fiesel, F.C.; Christenson, T.A.; Schroeder, A.S.; Zhang, L.; Bowles, E.; Behrouz, B.; et al. Progressive dopaminergic alterations and mitochondrial abnormalities in LRRK2 G2019S knock-in mice. Neurobiol. Dis. 2015, 78, 172-195.

72. Goldberg, M.S.; Fleming, S.M.; Palacino, J.J.; Cepeda, C.; Lam, H.A.; Bhatnagar, A.; Meloni, E.G.; Wu, N.; Ackerson, L.C.; Klapstein, G.J.; et al. Parkin-deficient mice exhibit nigrostriatal deficits but not loss of dopaminergic neurons. J. Biol. Chem. 2003, 278, 43628-43635.

73. Perez, F.A.; Palmiter, R.D. Parkin-deficient mice are not a robust model of parkinsonism. Proc. Natl. Acad. Sci. USA 2005, 102, 2174-2179.

74. Lopert, P.; Patel, M. Brain mitochondria from DJ-1 knockout mice show increased respiration-dependent hydrogen peroxide consumption. Redox Biol. 2014, 2, 667-672.

75. Akundi, R.S.; Huang, Z.; Eason, J.; Pandya, J.D.; Zhi, L.; Cass, W.A.; Sullivan, P.G.; Bueler, H. Increased mitochondrial calcium sensitivity and abnormal expression of innate immunity genes precede dopaminergic defects in Pink1-deficient mice. PLOS ONE 2011, 6, e16038.

76. Gispert, S.; Ricciardi, F.; Kurz, A.; Azizov, M.; Hoepken, H.H.; Becker, D.; Voos, W.; Leuner, K.; Muller, W.E.; Kudin, A.P.; et al. Parkinson phenotype in aged PINK1-deficient mice is accompanied by progressive mitochondrial dysfunction in absence of neurodegeneration. PLoS ONE 2009, 4, e5777.

77. Stichel, C.C.; Zhu, X.R.; Bader, V.; Linnartz, B.; Schmidt, S.; Lubbert, H. Mono- and double-mutant mouse models of Parkinson's disease display severe mitochondrial damage. Hum. Mol. Genet. 2007, 16, 2377-2393. 
78. Bonifati, V.; Oostra, B.A.; Heutink, P. Linking DJ-1 to neurodegeneration offers novel insights for understanding the pathogenesis of Parkinson's disease. J. Mol. Med. (Berl.) 2004, 82, 163-174.

79. Abou-Sleiman, P.M.; Healy, D.G.; Wood, N.W. Causes of Parkinson's disease: Genetics of DJ-1. Cell Tissue Res. 2004, 318, 185-188.

80. Zimprich, A.; Biskup, S.; Leitner, P.; Lichtner, P.; Farrer, M.; Lincoln, S.; Kachergus, J.; Hulihan, M.; Uitti, R.J.; Calne, D.B.; et al. Mutations in LRRK2 cause autosomal-dominant parkinsonism with pleomorphic pathology. Neuron 2004, 44, 601-607.

81. Paisan-Ruiz, C.; Jain, S.; Evans, E.W.; Gilks, W.P.; Simon, J.; van der Brug, M.; de Munain, A.L.; Aparicio, S.; Gil, A.M.; Khan, N.; et al. Cloning of the gene containing mutations that cause PARK8-linked Parkinson's disease. Neuron 2004, 44, 595-600.

82. West, A.B.; Moore, D.J.; Choi, C.; Andrabi, S.A.; Li, X.; Dikeman, D.; Biskup, S.; Zhang, Z.; Lim, K.L.; Dawson, V.L.; et al. Parkinson's disease-associated mutations in LRRK2 link enhanced GTP-binding and kinase activities to neuronal toxicity. Hum. Mol. Genet. 2007, 16, 223-232.

83. Cookson, M.R. The role of leucine-rich repeat kinase 2 (LRRK2) in Parkinson's disease. Nat. Rev. Neurosci. 2010, 11, 791-797.

84. West, A.B.; Moore, D.J.; Biskup, S.; Bugayenko, A.; Smith, W.W.; Ross, C.A.; Dawson, V.L.; Dawson, T.M. Parkinson's disease-associated mutations in leucine-rich repeat kinase 2 augment kinase activity. Proc. Natl. Acad. Sci. USA 2005, 102, 16842-16847.

85. Simon, H.H.; Saueressig, H.; Wurst, W.; Goulding, M.D.; O'Leary, D.D. Fate of midbrain dopaminergic neurons controlled by the engrailed genes. J. Neurosci. 2001, 21, 3126-3134.

86. Yu-chin Su, X.Q.; Impairment of mitochondrial dynamics: A target for the treatment of neurological disorders? Future Med. 2013, 8, 333-346.

87. Tanner, C.M.; Goldman, S.M. Epidemiology of Parkinson's disease. Neurol. Clin. 1996, 14, 317-35.

88. Caradoc-Davies, T.H.; Weatherall, M.; Dixon, G.S.; Caradoc-Davies, G.; Hantz, P. Is the prevalence of Parkinson's disease in New Zealand really changing? Acta Neurol. Scand. 1992, 86, 40-44.

89. Morgante, L.; Rocca, W.A.; di Rosa, A.E.; de Domenico, P.; Grigoletto, F.; Meneghini, F.; Reggio, A.; Savettieri, G.; Castiglione, M.G.; Patti, F.; et al. Prevalence of Parkinson's disease and other types of parkinsonism: A door-to-door survey in three Sicilian municipalities. The Sicilian Neuro-Epidemiologic Study (SNES) Group. Neurology 1992, 42, 1901-1907.

90. Mutch, W.J.; Dingwall-Fordyce, I.; Downie, A.W.; Paterson, J.G.; Roy, S.K. Parkinson's disease in a Scottish city. Br. Med. J. (Clin. Res. Ed.) 1986, 292, 534-536.

91. Polymeropoulos, M.H.; Higgins, J.J.; Golbe, L.I.; Johnson, W.G.; Ide, S.E.; di Iorio, G.; Sanges, G.; Stenroos, E.S.; Pho, L.T.; Schaffer, A.A.; et al. Mapping of a gene for Parkinson's disease to chromosome 4q21-q23. Science 1996, 274, 1197-1199.

92. Dekker, M.C.; Bonifati, V.; van Duijn, C.M. Parkinson's disease: Piecing together a genetic jigsaw. Brain 2003, 126, 1722-1733.

93. Langston, J.W. Epidemiology versus genetics in Parkinson's disease: Progress in resolving an age-old debate. Ann. Neurol. 1998, 44 (Suppl. 1), S45-S52. 
94. Bowers, W.J.; Howard, D.F.; Federoff, H.J. Gene therapeutic strategies for neuroprotection: Implications for Parkinson's disease. Exp. Neurol. 1997, 144, 58-68.

95. Kitada, T.; Asakawa, S.; Hattori, N.; Matsumine, H.; Yamamura, Y.; Minoshima, S.; Yokochi, M.; Mizuno, Y.; Shimizu, N. Mutations in the parkin gene cause autosomal recessive juvenile parkinsonism. Nature 1998, 392, 605-608.

96. Lincoln, S.; Vaughan, J.; Wood, N.; Baker, M.; Adamson, J.; Gwinn-Hardy, K.; Lynch, T.; Hardy, J.; Farrer, M. Low frequency of pathogenic mutations in the ubiquitin carboxy-terminal hydrolase gene in familial Parkinson's disease. Neuroreport 1999, 10, 427-429.

97. Golbe, L.I.; Di Iorio, G.; Bonavita, V.; Miller, D.C.; Duvoisin, R.C. A large kindred with autosomal dominant Parkinson's disease. Ann. Neurol. 1990, 27, 276-282.

98. Kruger, R.; Kuhn, W.; Muller, T.; Woitalla, D.; Graeber, M.; Kosel, S.; Przuntek, H.; Epplen, J.T.; Schols, L.; Riess, O. Ala30Pro mutation in the gene encoding alpha-synuclein in Parkinson's disease. Nat. Genet. 1998, 18, 106-108.

99. Polymeropoulos, M.H.; Lavedan, C.; Leroy, E.; Ide, S.E.; Dehejia, A.; Dutra, A.; Pike, B.; Root, H.; Rubenstein, J.; Boyer, R.; et al. Mutation in the alpha-synuclein gene identified in families with Parkinson's disease. Science 1997, 276, 2045-2047.

100. Pham, A.H.; Meng, S.; Chu, Q.N.; Chan, D.C. Loss of Mfn2 results in progressive, retrograde degeneration of dopaminergic neurons in the nigrostriatal circuit. Hum. Mol. Genet. 2012, 21, 4817-4826.

101. Lee, S.; Sterky, F.H.; Mourier, A.; Terzioglu, M.; Cullheim, S.; Olson, L.; Larsson, N.G. Mitofusin 2 is necessary for striatal axonal projections of midbrain dopamine neurons. Hum. Mol. Genet. 2012, 21, 4827-35.

102. Li, H.; Chen, Y.; Jones, A.F.; Sanger, R.H.; Collis, L.P.; Flannery, R.; McNay, E.C.; Yu, T.; Schwarzenbacher, R.; Bossy, B.; et al. Bcl-xL induces Drp1-dependent synapse formation in cultured hippocampal neurons. Proc. Natl. Acad. Sci. USA 2008, 105, 2169-2174.

103. Ishihara, N.; Nomura, M.; Jofuku, A.; Kato, H.; Suzuki, S.O.; Masuda, K.; Otera, H.; Nakanishi, Y.; Nonaka, I.; Goto, Y.; et al. Mitochondrial fission factor Drp1 is essential for embryonic development and synapse formation in mice. Nat. Cell. Biol. 2009, 11, 958-966.

104. Wakabayashi, J.; Zhang, Z.; Wakabayashi, N.; Tamura, Y.; Fukaya, M.; Kensler, T.W.; Iijima, M.; Sesaki, H. The dynamin-related GTPase Drp1 is required for embryonic and brain development in mice. J. Cell Biol. 2009, 186, 805-816.

105. Berthet, A.; Margolis, E.B.; Zhang, J.; Hsieh, I.; Zhang, J.; Hnasko, T.S.; Ahmad, J.; Edwards, R.H.; Sesaki, H.; Huang, E.J.; et al. Loss of mitochondrial fission depletes axonal mitochondria in midbrain dopamine neurons. J. Neurosci. 2014, 34, 14304-14317.

106. Zarranz, J.J.; Alegre, J.; Gomez-Esteban, J.C.; Lezcano, E.; Ros, R.; Ampuero, I.; Vidal, L.; Hoenicka, J.; Rodriguez, O.; Atares, B.; et al. The new mutation, E46K, of alpha-synuclein causes Parkinson and Lewy body dementia. Ann. Neurol. 2004, 55, 164-173.

107. Bonifati, V.; Rizzu, P.; Squitieri, F.; Krieger, E.; Vanacore, N.; van Swieten, J.C.; Brice, A.; van Duijn, C.M.; Oostra, B.; Meco, G.; et al. DJ-1(PARK7), a novel gene for autosomal recessive, early onset parkinsonism. Neurol. Sci. 2003, 24, 159-160.

108. Iwatsubo, T.; Ito, G.; Takatori, S.; Hannno, Y.; Kuwahara, T. Pathogenesis of Parkinson's disease: Implications from familial Parkinson's disease. Rinsho Shinkeigaku 2005, 45, 899-901. 
109. Bialecka, M.; Hui, S.; Klodowska-Duda, G.; Opala, G.; Tan, E.K.; Drozdzik, M. Analysis of LRRK 2 G 2019 S and I 2020 T mutations in Parkinson's disease. Neurosci. Lett. 2005, 390, 1-3.

110. Smith, R.G. The aging process: Where are the drug opportunities? Curr. Opin. Chem. Biol. 2000, 4, 371-376.

111. Le, W.; Conneely, O.M.; He, Y.; Jankovic, J.; Appel, S.H. Reduced Nurr1 expression increases the vulnerability of mesencephalic dopamine neurons to MPTP-induced injury. J. Neurochem. 1999, 73, 2218-2221.

112. Xiao, Q.; Castillo, S.O.; Nikodem, V.M. Distribution of messenger RNAs for the orphan nuclear receptors Nurr1 and Nur77 (NGFI-B) in adult rat brain using in situ hybridization. Neuroscience 1996, 75, 221-230.

113. Rakovic, A.; Grunewald, A.; Seibler, P.; Ramirez, A.; Kock, N.; Orolicki, S.; Lohmann, K.; Klein, C. Effect of endogenous mutant and wild-type PINK1 on Parkin in fibroblasts from Parkinson disease patients. Hum. Mol. Genet. 2010, 19, 3124-3137.

114. Rakovic, A.; Grunewald, A.; Kottwitz, J.; Bruggemann, N.; Pramstaller, P.P.; Lohmann, K.; Klein, C. Mutations in PINK1 and Parkin Impair Ubiquitination of Mitofusins in Human Fibroblasts. PLoS ONE 2011, 6, e16746.

115. Jin, H.J.; Li, C.G. Tanshinone IIA and Cryptotanshinone Prevent Mitochondrial Dysfunction in Hypoxia-Induced H9c2 Cells: Association to Mitochondrial ROS, Intracellular Nitric Oxide, and Calcium Levels. Evid. Based Complement. Alternat. Med. 2013, 2013, 610694.

116. Poole, A.C.; Thomas, R.E.; Andrews, L.A.; McBride, H.M.; Whitworth, A.J.; Pallanck, L.J. The PINK1/Parkin pathway regulates mitochondrial morphology. Proc. Natl. Acad. Sci. USA 2008, 105, 1638-1643.

117. Yang, Y.; Ouyang, Y.; Yang, L.; Beal, M.F.; McQuibban, A.; Vogel, H.; Lu, B. Pink1 regulates mitochondrial dynamics through interaction with the fission/fusion machinery. Proc. Natl. Acad. Sci. USA 2008, 105, 7070-7075.

118. Yu, W.; Sun, Y.; Guo, S.; Lu, B. The PINK1/Parkin pathway regulates mitochondrial dynamics and function in mammalian hippocampal and dopaminergic neurons. Hum. Mol. Genet. 2011, 20, 3227-3240.

119. Wang, X.; Petrie, T.G.; Liu, Y.; Liu, J.; Fujioka, H.; Zhu, X. Parkinson's disease-associated DJ-1 mutations impair mitochondrial dynamics and cause mitochondrial dysfunction. J. Neurochem. 2012, 121, 830-839.

120. Ryan, B.J.; Hoek, S.; Fon, E.A.; Wade-Martins, R. Mitochondrial dysfunction and mitophagy in Parkinson's: From familial to sporadic disease. Trends Biochem. Sci. 2015, 40, 200-210.

121. Niu, J.; Yu, M.; Wang, C.; Xu, Z. Leucine-rich repeat kinase 2 disturbs mitochondrial dynamics via Dynamin-like protein. J. Neurochem. 2012, 122, 650-658.

122. Wang, X.; Yan, M.H.; Fujioka, H.; Liu, J.; Wilson-Delfosse, A.; Chen, S.G.; Perry, G.; Casadesus, G.; Zhu, X. LRRK2 regulates mitochondrial dynamics and function through direct interaction with DLP1. Hum. Mol. Genet. 2012, 21, 1931-1944.

123. Su, Y.C.; Qi, X. Inhibition of excessive mitochondrial fission reduced aberrant autophagy and neuronal damage caused by LRRK2 G2019S mutation. Hum. Mol. Genet. 2013, 22, 4545-4561. 
124. Guo, X.; Disatnik, M.H.; Monbureau, M.; Shamloo, M.; Mochly-Rosen, D.; Qi, X. Inhibition of mitochondrial fragmentation diminishes Huntington's disease-associated neurodegeneration. J. Clin. Investig. 2013, 123, 5371-5388.

125. Qi, X.; Qvit, N.; Su, Y.C.; Mochly-Rosen, D. A novel Drp1 inhibitor diminishes aberrant mitochondrial fission and neurotoxicity. J. Cell Sci. 2013, 126, 789-802.

126. Yamamoto, A.; Yue, Z. Autophagy and its normal and pathogenic states in the brain. Annu. Rev. Neurosci. 2014, 37, 55-78.

127. Redmann, M.; Dodson, M.; Boyer-Guittaut, M.; Darley-Usmar, V.; Zhang, J. Mitophagy mechanisms and role in human diseases. Int. J. Biochem. Cell Biol. 2014, 53, 127-33.

128. Fass, E.; Amar, N.; Elazar, Z. Identification of essential residues for the C-terminal cleavage of the mammalian LC3: A lesson from yeast Atg8. Autophagy 2007, 3, 48-50.

129. Kabeya, Y.; Mizushima, N.; Ueno, T.; Yamamoto, A.; Kirisako, T.; Noda, T.; Kominami, E.; Ohsumi, Y.; Yoshimori, T. LC3, a mammalian homologue of yeast Apg8p, is localized in autophagosome membranes after processing. EMBO J. 2000, 19, 5720-5728.

130. Kanki, T.; Wang, K.; Cao, Y.; Baba, M.; Klionsky, D.J. Atg32 is a mitochondrial protein that confers selectivity during mitophagy. Dev. Cell 2009, 17, 98-109.

131. Okamoto, K.; Kondo-Okamoto, N.; Ohsumi, Y. Mitochondria-anchored receptor Atg32 mediates degradation of mitochondria via selective autophagy. Dev. Cell 2009, 17, 87-97.

132. Liu, L.; Feng, D.; Chen, G.; Chen, M.; Zheng, Q.; Song, P.; Ma, Q.; Zhu, C.; Wang, R.; Qi, W.; et al. Mitochondrial outer-membrane protein FUNDC1 mediates hypoxia-induced mitophagy in mammalian cells. Nat. Cell Biol. 2012, 14, 177-185.

133. Narendra, D.; Kane, L.A.; Hauser, D.N.; Fearnley, I.M.; Youle, R.J. p62/SQSTM1 is required for Parkin-induced mitochondrial clustering but not mitophagy; VDAC1 is dispensable for both. Autophagy 2010, 6, 1090-1106.

134. Shi, R.Y.; Zhu, S.H.; Li, V.; Gibson, S.B.; Xu, X.S.; Kong, J.M. BNIP3 interacting with LC3 triggers excessive mitophagy in delayed neuronal death in stroke. CNS Neurosci. Ther. 2014, 20 , $1045-1055$.

135. Strappazzon, F.; Nazio, F.; Corrado, M.; Cianfanelli, V.; Romagnoli, A.; Fimia, G.M.; Campello, S.; Nardacci, R.; Piacentini, M.; Campanella, M.; et al. AMBRA1 is able to induce mitophagy via LC3 binding, regardless of PARKIN and p62/SQSTM1. Cell. Death Differ. 2015, $22,419-432$.

136. Johansen, T.; Lamark, T. Selective autophagy mediated by autophagic adapter proteins. Autophagy 2011, 7, 279-296.

137. Wu, F.; Xu, H.D.; Guan, J.J.; Hou, Y.S.; Gu, J.H.; Zhen, X.C., Qin, Z.H. Rotenone impairs autophagic flux and lysosomal functions in Parkinson's disease. Neuroscience 2015, 284, 900-911.

138. Arsikin, K.; Kravic-Stevovic, T.; Jovanovic, M.; Ristic, B.; Tovilovic, G.; Zogovic, N.; Bumbasirevic, V.; Trajkovic, V.; Harhaji-Trajkovic, L. Autophagy-dependent and -independent involvement of AMP-activated protein kinase in 6-hydroxydopamine toxicity to SH-SY5Y neuroblastoma cells. Biochim. Biophys. Acta 2012, 1822, 1826-1836.

139. Youle, R.J.; Narendra, D.P. Mechanisms of mitophagy. Nat. Rev. Mol. Cell Biol. 2011, 12, 9-14.

140. Narendra, D.P.; Youle, R.J. Targeting mitochondrial dysfunction: Role for PINK1 and Parkin in mitochondrial quality control. Antioxid. Redox Signal. 2011, 14, 1929-1938. 
141. Ashrafi, G.; Schlehe, J.S.; LaVoie, M.J.; Schwarz, T.L. Mitophagy of damaged mitochondria occurs locally in distal neuronal axons and requires PINK1 and Parkin. J. Cell Biol. 2014, 206, $655-670$.

142. Geisler, S.; Holmstrom, K.M.; Skujat, D.; Fiesel, F.C.; Rothfuss, O.C.; Kahle, P.J.; Springer, W. PINK1/Parkin-mediated mitophagy is dependent on VDAC1 and p62/SQSTM1. Nat. Cell Biol. 2010, 12, 119-131.

143. Rakovic, A.; Shurkewitsch, K.; Seibler, P.; Grunewald, A.; Zanon, A.; Hagenah, J.; Krainc, D.; Klein, C. Phosphatase and tensin homolog (PTEN)-induced putative kinase 1 (PINK1)-dependent ubiquitination of endogenous Parkin attenuates mitophagy: Study in human primary fibroblasts and induced pluripotent stem cell-derived neurons. J. Biol. Chem. 2013, 288, 2223-2237.

144. McCoy, M.K.; Cookson, M.R. DJ-1 regulation of mitochondrial function and autophagy through oxidative stress. Autophagy 2011, 7, 531-532.

145. Thomas, K.J.; McCoy, M.K.; Blackinton, J.; Beilina, A.; van der Brug, M.; Sandebring, A.; Miller, D.; Maric, D.; Cedazo-Minguez, A.; Cookson, M.R. DJ-1 acts in parallel to the PINK1/parkin pathway to control mitochondrial function and autophagy. Hum. Mol. Genet. 2011, 20, 40-50.

146. Irrcher, I.; Aleyasin, H.; Seifert, E.L.; Hewitt, S.J.; Chhabra, S.; Phillips, M.; Lutz, A.K.; Rousseaux, M.W.; Bevilacqua, L.; Jahani-Asl, A.; et al. Loss of the Parkinson's disease-linked gene DJ-1 perturbs mitochondrial dynamics. Hum. Mol. Genet. 2010, 19, 3734-46.

147. Tang, B.; Xiong, H.; Sun, P.; Zhang, Y.; Wang, D.; Hu, Z.; Zhu, Z.; Ma, H.; Pan, Q.; Xia, J.H.; et al. Association of PINK1 and DJ-1 confers digenic inheritance of early-onset Parkinson's disease. Hum. Mol. Genet. 2006, 15, 1816-1825.

148. Xiong, H.; Wang, D.; Chen, L.; Choo, Y.S.; Ma, H.; Tang, C.; Xia, K.; Jiang, W.; Ronai, Z.; Zhuang, X.; et al. Parkin, PINK1, and DJ-1 form a ubiquitin E3 ligase complex promoting unfolded protein degradation. J. Clin. Investig. 2009, 119, 650-660.

149. Plowey, E.D.; Cherra, S.J., 3rd; Liu, Y.J.; Chu, C.T. Role of autophagy in G2019S-LRRK2-associated neurite shortening in differentiated SH-SY5Y cells. J. Neurochem. 2008, 105, 1048-1056.

150. Yakhine-Diop, S.M.; Bravo-San Pedro, J.M.; Gomez-Sanchez, R.; Pizarro-Estrella, E.; Rodriguez-Arribas, M.; Climent, V.; Aiastui, A.; Lopez de Munain, A.; Fuentes, J.M.; Gonzalez-Polo, R.A. G2019S LRRK2 mutant fibroblasts from Parkinson's disease patients show increased sensitivity to neurotoxin 1-methyl-4-phenylpyridinium dependent of autophagy. Toxicology 2014, 324, 1-9.

151. Sanchez-Danes, A.; Richaud-Patin, Y.; Carballo-Carbajal, I.; Jimenez-Delgado, S.; Caig, C.; Mora, S.; di Guglielmo, C.; Ezquerra, M.; Patel, B.; Giralt, A.; et al. Disease-specific phenotypes in dopamine neurons from human iPS-based models of genetic and sporadic Parkinson's disease. EMBO Mol. Med. 2012, 4, 380-395.

152. Lachenmayer, M.L.; Yue, Z. Genetic animal models for evaluating the role of autophagy in etiopathogenesis of Parkinson disease. Autophagy 2012, 8, 1837-1838.

153. Alegre-Abarrategui, J.; Christian, H.; Lufino, M.M.; Mutihac, R.; Venda, L.L.; Ansorge, O.; Wade-Martins, R. LRRK2 regulates autophagic activity and localizes to specific membrane microdomains in a novel human genomic reporter cellular model. Hum. Mol. Genet. 2009, 18, $4022-4034$. 
154. Saez-Atienzar, S.; Bonet-Ponce, L.; Blesa, J.R.; Romero, F.J.; Murphy, M.P.; Jordan, J.; Galindo, M.F. The LRRK2 inhibitor GSK2578215A induces protective autophagy in SH-SY5Y cells: Involvement of Drp-1-mediated mitochondrial fission and mitochondrial-derived ROS signaling. Cell Death Dis. 2014, 5, e1368.

155. Gomez-Suaga, P.; Luzon-Toro, B.; Churamani, D.; Zhang, L.; Bloor-Young, D.; Patel, S.; Woodman, P.G.; Churchill, G.C.; Hilfiker, S. Leucine-rich repeat kinase 2 regulates autophagy through a calcium-dependent pathway involving NAADP. Hum. Mol. Genet. 2012, 21, 511-525.

156. Bravo-San Pedro, J.M.; Niso-Santano, M.; Gomez-Sanchez, R.; Pizarro-Estrella, E.; Aiastui-Pujana, A.; Gorostidi, A.; Climent, V.; Lopez de Maturana, R.; Sanchez-Pernaute, R.; Lopez de Munain, A.; et al. The LRRK2 G2019S mutant exacerbates basal autophagy through activation of the MEK/ERK pathway. Cell. Mol. Life Sci. 2013, 70, 121-136.

157. Gomez-Suaga, P.; Hilfiker, S. LRRK2 as a modulator of lysosomal calcium homeostasis with downstream effects on autophagy. Autophagy 2012, 8, 692-693.

158. Orenstein, S.J.; Kuo, S.H.; Tasset, I.; Arias, E.; Koga, H.; Fernandez-Carasa, I.; Cortes, E.; Honig, L.S.; Dauer, W.; Consiglio, A.; et al. Interplay of LRRK2 with chaperone-mediated autophagy. Nat. Neurosci. 2013, 16, 394-406.

159. Su, Y.C.; Guo, X.;Qi, X. Threonine 56 phosphorylation of Bcl-2 is required for LRRK2 G2019S-induced mitochondrial depolarization and autophagy. Biochim. Biophys. Acta 2015, 1852, 12-21.

160. Ramsay, R.R.; Salach, J.I.; Singer, T.P. Uptake of the neurotoxin 1-methyl-4-phenylpyridine $(\mathrm{MPP}+)$ by mitochondria and its relation to the inhibition of the mitochondrial oxidation of $\mathrm{NAD}^{+}$-linked substrates by MPP+. Biochem. Biophys. Res. Commun. 1986, 134, 743-748.

161. Marey-Semper, I.; Gelman, M.; Levi-Strauss, M. The high sensitivity to rotenone of striatal dopamine uptake suggests the existence of a constitutive metabolic deficiency in dopaminergic neurons from the substantia nigra. Eur. J. Neurosci. 1993, 5, 1029-1034.

162. Chinta, S.J.; Mallajosyula, J.K.; Rane, A.; Andersen, J.K. Mitochondrial alpha-synuclein accumulation impairs complex I function in dopaminergic neurons and results in increased mitophagy in vivo. Neurosci. Lett. 2010, 486, 235-239.

163. Devi, L.; Raghavendran, V.; Prabhu, B.M.; Avadhani, N.G.; Anandatheerthavarada, H.K. Mitochondrial import and accumulation of alpha-synuclein impair complex I in human dopaminergic neuronal cultures and Parkinson disease brain. J. Biol. Chem. 2008, 283, 9089-9100.

164. Martin, L.J.; Pan, Y.; Price, A.C.; Sterling, W.; Copeland, N.G.; Jenkins, N.A.; Price, D.L.; Lee, M.K. Parkinson's disease alpha-synuclein transgenic mice develop neuronal mitochondrial degeneration and cell death. $J$. Neurosci. 2006, 26, 41-50.

165. Zuo, L.; Motherwell, M.S. The impact of reactive oxygen species and genetic mitochondrial mutations in Parkinson's disease. Gene 2013, 532, 18-23.

166. Nakamura, T.; Prikhodko, O.A.; Pirie, E.; Nagar, S.; Akhtar, M.W.; Oh, C.K.; McKercher, S.R.; Ambasudhan, R.; Okamoto, S.I.; Lipton, S.A. Aberrant protein S-nitrosylation contributes to the pathophysiology of neurodegenerative diseases. Neurobiol. Dis. 2015, doi:10.1016/j.nbd.2015.03.017. 
167. Van Muiswinkel, F.L.; Steinbusch, H.W.; Drukarch, B.; de Vente, J. Identification of NO-producing and -receptive cells in mesencephalic transplants in a rat model of Parkinson's disease: A study using NADPH-d enzyme- and NOSc/cGMP immunocytochemistry. Ann. N. Y. Acad. Sci. 1994, 738, 289-304.

168. Gu, Z.; Nakamura, T.; Lipton, S.A. Redox reactions induced by nitrosative stress mediate protein misfolding and mitochondrial dysfunction in neurodegenerative diseases. Mol. Neurobiol. 2010, $41,55-72$.

169. Levecque, C.; Elbaz, A.; Clavel, J.; Richard, F.; Vidal, J.S.; Amouyel, P.; Tzourio, C.; Alperovitch, A.; Chartier-Harlin, M.C. Association between Parkinson's disease and polymorphisms in the nNOS and iNOS genes in a community-based case-control study. Hum. Mol. Genet. 2003, 12, 79-86.

170. Joniec, I.; Ciesielska, A.; Kurkowska-Jastrzebska, I.; Przybylkowski, A.; Czlonkowska, A.; Czlonkowski, A. Age- and sex-differences in the nitric oxide synthase expression and dopamine concentration in the murine model of Parkinson's disease induced by 1-methyl-4-phenyl-1,2,3,6-tetrahydropyridine. Brain Res. 2009, 1261, 7-19.

171. Watanabe, Y.; Kato, H.; Araki, T. Protective action of neuronal nitric oxide synthase inhibitor in the MPTP mouse model of Parkinson's disease. Metab. Brain Dis. 2008, 23, 51-69.

172. Castagnoli, K.; Palmer, S.; Castagnoli, N., Jr. Neuroprotection by (R)-deprenyl and 7-nitroindazole in the MPTP C57BL/6 mouse model of neurotoxicity. Neurobiology (Bp) 1999, 7, 135-149.

173. Dolezal, P.; Likic, V.; Tachezy, J.; Lithgow, T. Evolution of the molecular machines for protein import into mitochondria. Science 2006, 313, 314-318.

174. De Marcos-Lousa, C.; Sideris, D.P.; Tokatlidis, K. Translocation of mitochondrial inner-membrane proteins: Conformation matters. Trends Biochem. Sci. 2006, 31, 259-267.

175. Baker, M.J.; Frazier, A.E.; Gulbis, J.M.; Ryan, M.T. Mitochondrial protein-import machinery: Correlating structure with function. Trends Cell. Biol. 2007, 17, 456-464.

176. Gottschalk, W.K.; Lutz, M.W.; He, Y.T.; Saunders, A.M.; Burns, D.K.; Roses, A.D.; Chiba-Falek, O. The Broad Impact of TOM40 on Neurodegenerative Diseases in Aging. J. Parkinsons Dis. Alzheimers Dis. 2014, 1, 12.

177. Bender, A.; Desplats, P.; Spencer, B.; Rockenstein, E.; Adame, A.; Elstner, M.; Laub, C.; Mueller, S.; Koob, A.O.; Mante, M.; et al. TOM40 mediates mitochondrial dysfunction induced by alpha-synuclein accumulation in Parkinson's disease. PLOS ONE 2013, 8, e62277.

178. Okatsu, K.; Kimura, M.; Oka, T.; Tanaka, K.; Matsuda, N. Unconventional PINK1 localization to the outer membrane of depolarized mitochondria drives Parkin recruitment. J. Cell Sci. 2015, $128,964-978$.

179. Kato, H.; Lu, Q.; Rapaport, D.; Kozjak-Pavlovic, V. Tom70 is essential for PINK1 import into mitochondria. PLoS ONE 2013, 8, e58435.

180. Cooper, O.; Seo, H.; Andrabi, S.; Guardia-Laguarta, C.; Graziotto, J.; Sundberg, M.; McLean, J.R.; Carrillo-Reid, L.; Xie, Z.; Osborn, T.; et al. Pharmacological rescue of mitochondrial deficits in iPSC-derived neural cells from patients with familial Parkinson's disease. Sci. Transl. Med. 2012, 4, 141 ra90. 
181. Reinhardt, P.; Schmid, B.; Burbulla, L.F.; Schondorf, D.C.; Wagner, L.; Glatza, M.; Hoing, S.; Hargus, G.; Heck, S.A.; Dhingra, A.; et al. Genetic correction of a LRRK2 mutation in human iPSCs links parkinsonian neurodegeneration to ERK-dependent changes in gene expression. Cell. Stem Cell. 2013, 12, 354-367.

182. Toyoda, Y.; Erkut, C.; Pan-Montojo, F.; Boland, S.; Stewart, M.P.; Muller, D.J.; Wurst, W.; Hyman, A.A.; Kurzchalia, T.V. Products of the Parkinson's disease-related glyoxalase DJ-1, D-lactate and glycolate, support mitochondrial membrane potential and neuronal survival. Biol. Open 2014, 3, 777-784.

183. Daher, J.P.; Abdelmotilib, H.A.; Hu, X.; Volpicelli-Daley, L.A.; Moehle, M.S.; Fraser, K.B.; Needle, E.; Chen, Y.; Steyn, S.J.; Galatsis, P.; et al. LRRK2 Pharmacological Inhibition Abates alpha-Synuclein Induced Neurodegeneration. J. Biol. Chem. 2015, 290, 19433-19444.

184. Li, T.; He, X.; Thomas, J.M.; Yang, D.; Zhong, S.; Xue, F.; Smith, W.W. A novel GTP-binding inhibitor, FX2149, attenuates LRRK2 toxicity in Parkinson's disease models. PLoS ONE 2015, 10, e0122461.

185. Chiu, C.C.; Yeh, T.H.; Lai, S.C.; Wu-Chou, Y.H.; Chen, C.H.; Mochly-Rosen, D.; Huang, Y.C.; Chen, Y.J.; Chen, C.L.; Chang, Y.M.; et al. Neuroprotective effects of aldehyde dehydrogenase 2 activation in rotenone-induced cellular and animal models of parkinsonism. Exp. Neurol. 2015, $263,244-253$.

186. Richter, F.; Gao, F.; Medvedeva, V.; Lee, P.; Bove, N.; Fleming, S.M.; Michaud, M.; Lemesre, V.; Patassini, S.; de La Rosa, K.; et al. Chronic administration of cholesterol oximes in mice increases transcription of cytoprotective genes and improves transcriptome alterations induced by alpha-synuclein overexpression in nigrostriatal dopaminergic neurons. Neurobiol. Dis. 2014, 69, 263-275.

187. Rappold, P.M.; Cui, M.; Grima, J.C.; Fan, R.Z.; de Mesy-Bentley, K.L.; Chen, L.; Zhuang, X.; Bowers, W.J.; Tieu, K. Drp1 inhibition attenuates neurotoxicity and dopamine release deficits in vivo. Nat. Commun. 2014, 5, 5244.

188. Mena, N.P.; Garcia-Beltran, O.; Lourido, F.; Urrutia, P.J.; Mena, R.; Castro-Castillo, V.; Cassels, B.K.; Nunez, M.T. The novel mitochondrial iron chelator 5-((methylamino)methyl)-8-hydroxyquinoline protects against mitochondrial-induced oxidative damage and neuronal death. Biochem. Biophys. Res. Commun. 2015, 463, 787-792.

189. Jiang, J.; Zuo, Y.; Gu, Z. Rapamycin protects the mitochondria against oxidative stress and apoptosis in a rat model of Parkinson's disease. Int. J. Mol. Med. 2013, 31, 825-832.

190. Xiong, N.; Xiong, J.; Khare, G.; Chen, C.; Huang, J.; Zhao, Y.; Zhang, Z.; Qiao, X.; Feng, Y.; Reesaul, H.; et al. Edaravone guards dopamine neurons in a rotenone model for Parkinson's disease. PLoS ONE 2011, 6, e20677.

191. Dabbeni-Sala, F.; di Santo, S.; Franceschini, D.; Skaper, S.D.; Giusti, P. Melatonin protects against 6-OHDA-induced neurotoxicity in rats: A role for mitochondrial complex I activity. FASEB J. 2001, 15, 164-170

192. Zaitone, S.A.; Hammad, L.N.; Farag, N.E. Antioxidant potential of melatonin enhances the response to L-dopa in 1-methyl 4-phenyl 1,2,3,6-tetrahydropyridine-parkinsonian mice. Pharmacol. Rep. 2013, 65, 1213-1226. 
193. Karuppagounder, S.S.; Madathil, S.K.; Pandey, M.; Haobam, R.; Rajamma, U.; Mohanakumar, K.P. Quercetin up-regulates mitochondrial complex-I activity to protect against programmed cell death in rotenone model of Parkinson's disease in rats. Neuroscience 2013, 236, 136-148.

194. Jayaraj, R.L.; Elangovan, N.; Dhanalakshmi, C.; Manivasagam, T.; Essa, M.M. CNB-001, a novel pyrazole derivative mitigates motor impairments associated with neurodegeneration via suppression of neuroinflammatory and apoptotic response in experimental Parkinson's disease mice. Chem. Biol. Interact. 2014, 220, 149-157.

195. Abdin, A.A.; Sarhan, N.I. Intervention of mitochondrial dysfunction-oxidative stress-dependent apoptosis as a possible neuroprotective mechanism of alpha-lipoic acid against rotenone-induced parkinsonism and L-dopa toxicity. Neurosci. Res. 2011, 71, 387-395.

196. Kaur, H.; Chauhan, S.; Sandhir, R. Protective effect of lycopene on oxidative stress and cognitive decline in rotenone induced model of Parkinson's disease. Neurochem. Res. 2011, 36, 1435-1443.

197. Chen, C.H.; Budas, G.R.; Churchill, E.N.; Disatnik, M.H.; Hurley, T.D.; Mochly-Rosen, D. Activation of aldehyde dehydrogenase-2 reduces ischemic damage to the heart. Science $\mathbf{2 0 0 8}$, 321, 1493-1145.

198. Bordet, T.; Buisson, B.; Michaud, M.; Drouot, C.; Galea, P.; Delaage, P.; Akentieva, N.P.; Evers, A.S.; Covey, D.F.; Ostuni, M.A.; et al. Identification and characterization of cholest-4-en-3-one, oxime (TRO19622), a novel drug candidate for amyotrophic lateral sclerosis. J. Pharmacol. Exp. Ther. 2007, 322, 709-720.

199. Gouarne, C.; Tracz, J.; Paoli, M.G.; Deluca, V.; Seimandi, M.; Tardif, G.; Xilouri, M.; Stefanis, L.; Bordet, T.; Pruss, R.M. Protective role of olesoxime against wild-type alphasynuclein-induced toxicity in human neuronally differentiated SHSY-5Y cells. Br. J. Pharmacol. 2015, 172, 235-245.

200. Fernandez-Moriano, C.; Gonzalez-Burgos, E.; Gomez-Serranillos, M.P. Mitochondria-Targeted Protective Compounds in Parkinson's and Alzheimer's Diseases. Oxid. Med. Cell. Longev. 2015, $2015,408927$.

201. Valadas, J.S.; Vos, M.; Verstreken, P. Therapeutic strategies in Parkinson's disease: What we have learned from animal models. Ann. N. Y. Acad. Sci. 2015, 1338, 16-37.

202. Procaccio, V.; Bris, C.; de la Barca, J.M.C.; Oca, F.; Chevrollier, A.; Amati-Bonneau, P.; Bonneau, D.; Reynier, P. Perspectives of drug-based neuroprotection targeting mitochondria. Rev. Neurol. (Paris) 2014, 170, 390-400.

203. Yadav, A.; Agarwal, S.; Tiwari, S.K.; Chaturvedi, R.K. Mitochondria: Prospective targets for neuroprotection in Parkinson's disease. Curr. Pharm. Des. 2014, 20, 5558-5573.

(C) 2015 by the authors; licensee MDPI, Basel, Switzerland. This article is an open access article distributed under the terms and conditions of the Creative Commons Attribution license (http://creativecommons.org/licenses/by/4.0/). 